\title{
A Survey of Medical Students' Use of Nutrition Resources and Perceived Competency in Providing Basic Nutrition Education
}

\author{
Rebecca Connor, Lynn Cialdella-Kam, and Stephanie R. Harris \\ Department of Nutrition, School of Medicine, Case Western Reserve University, 10900 Euclid Avenue, Cleveland, OH 44120, USA \\ Correspondence should be addressed to Stephanie R. Harris; sra18@case.edu
}

Received 3 September 2014; Revised 3 November 2014; Accepted 13 November 2014

Academic Editor: Martin Kohlmeier

Copyright ( 2015 Rebecca Connor et al. This is an open access article distributed under the Creative Commons Attribution License, which permits unrestricted use, distribution, and reproduction in any medium, provided the original work is properly cited.

Purpose. The aims of this study were to assess where medical students obtain their nutrition information and their self-perceived level of competency in providing basic nutrition education to patients. Methods. A survey was distributed to all first through fourth year medical students at Case Western Reserve University $(n=657)$. For statistical analysis, data was expressed as percentages of total responses and binomial regression was used to answer the study hypotheses. Results. The survey response rate was $47 \%$. Fortytwo percent of respondents selected a majority of professional nutrition resources $(n=132)$ as their most commonly used nutrition resources, $38 \%$ selected a majority of consumer resources $(n=119)$, and $20 \%$ selected "I do not use nutrition resources" $(n=61)$. The most popular nutrition resource selected was consumer websites. Seventy percent of respondents reported feeling competent in their ability to provide basic nutrition education to patients $(n=219)$. Conclusion. Medical students seem to feel competent in their ability to give basic nutrition education to patients, but they may be obtaining nutrition information from unreliable consumerbased resources. To help increase the provision of sound nutritional guidance, medical students should be taught to use reliable nutrition resources, as well as the value of referring patients to registered dietitians.

\section{Introduction}

Nutrition-related chronic diseases are growing in prevalence in the USA; $35.9 \%$ of adults are obese, $8.1 \%$ have diagnosed diabetes, and $24 \%$ of deaths are caused by heart disease [1]. Physicians are often the first line of defense against chronic disease, as they are the first to communicate with patients about disease risk factors and prevention. Referring patients with nutrition-related health problems to registered dietitians (RDs) is often the best decision for a patient. However, it remains important that physicians feel competent in their ability to provide basic nutrition education and that they obtain nutrition information from reliable sources.

The American Academy of Family Physicians established nutrition competencies that medical residents should have at the end of training. One is to "be able to counsel patients regarding nutritional recommendations in a culturallysensitive manner" [2]. Healthy People 2020 includes an objective to increase the number of patients receiving nutritional counseling and education from physicians [3]. In 2007, 12.2\% of patients received nutritional counseling during physician visits. By 2020, the goal is that this percentage will increase to $15.2 \%[3]$.

Reports have found that physicians agree on nutrition being an important component of their practice but feel incompetent in their ability to provide nutritional counseling to patients [4-8]. Surveyed physicians have identified barriers to providing nutritional counseling. One is a lack of nutrition training in medical school. In 2005, 51.1\% of US medical school graduates reported in the Association of American Medical Colleges Medical School Graduation Questionnaire that they received insufficient nutrition education during undergraduate medical school education $[9,10]$. More recent questionnaires have not asked graduates about their nutrition education. From 1999 to 2009, 62-73\% of US medical schools were not meeting the minimum suggested 25 hours of nutrition education recommended by the National Academy of Sciences [4, 11-13]. The National Academy of Sciences 
also reported that the average number of nutrition education hours in medical school had dropped from 21 hours in 1985 to 19.6 hours in $2009[4,14]$.

Direct observations of 8000 patient visits with family physicians in 2002 and 2004 indicated that as few as $24 \%$ of primary care physicians (PCPs) provide nutritional counseling $[15,16]$. In addition, in 2006 , only one-third of Americans reported receiving nutrition information from physicians in the past $[17,18]$. Physicians are often viewed as the most trusted source of nutrition information by surveyed consumers, and more than 25\% of PCP visits involve a nutrition-related reason [17]. Furthermore, many physicians believe nutrition education is their responsibility, but few are actually giving nutrition education, and when they do, time is extremely limited $[5,8,15,16,19]$.

Because physicians report receiving insufficient nutrition education during medical school, it makes sense to assume that they would turn to other sources for their nutrition information to gain knowledge. In 1995, a survey was sent to a representative random sample of active US physicians practicing in general practice, internal medicine, or pediatrics. The survey asked them to identify what sources they used to obtain nutrition information. Sixty-nine percent reported acquiring nutrition information from medical journals, 58\% from dietitians, $46 \%$ from seminars and conferences, and $16 \%$ from nutrition journals, nutrition texts, and popular magazines [8]. In a more recent 2008 Dutch study, $61 \%$ of surveyed physicians reported searching the Internet for nutrition information, although the websites used were unspecified [20]. It is important that physicians choose professional, reliable nutrition resources so that the information they provide to patients is accurate.

To the best of our knowledge, few studies have assessed what nutrition resources medical students utilize or their feelings of preparedness toward providing basic nutrition education to patients. All research about the latter topics appears to be related to physicians. However, it is important to assess medical students because medical school is usually where physicians first receive nutrition education. During this time, students begin to develop habits regarding what nutrition resources will be their most frequently used sources of information. In addition, medical school is likely where many students are first exposed to the nutrition-related topics they will commonly have to discuss with patients. Thus, if medical students feel adequately prepared to give basic nutrition education and are taught to use reliable nutrition resources, they will be much more likely to provide sound nutritional guidance to patients once they become practicing physicians.

Medical students at Case Western Reserve University (CWRU) in Cleveland, Ohio, receive nutrition education in the classroom during their first year of medical school [21]. During their third year, they participate in various clinical rotations, in which they likely encounter patients with nutritional concerns and work on interdisciplinary teams that include RDs [21]. However, whether the latter exposure to nutrition provides them with the ability to identify reliable sources of nutrition information and promotes feelings of competency in providing basic nutrition education to patients is unknown. The objectives of this study were to assess where CWRU medical students get their nutrition information and their perceived competency in providing basic nutrition education to patients according to the 2010 Dietary Guidelines for Americans (DGAs). The DGAs were chosen as a reference for basic nutrition education topics because they represent a professional nutrition resource readily available to physicians. In addition, the DGAs include recommendations for the general population that emphasize an overall healthy diet [22]. The study hypotheses were that (i) a majority of medical students at CWRU who responded to the survey would identify consumer and not professional nutrition resources as their top sources of nutrition information, (ii) a majority of these medical students would not feel competent to provide basic nutrition education according to the DGAs, and (iii) self-perceived level of competency in providing basic nutrition education would increase as year in medical school increases.

\section{Methods}

A survey was developed asking medical students to provide information about their year in medical school, gender, top three sources for nutrition information, and perceived competency in providing basic nutrition education to patients. The survey was distributed in February 2013 via Research Electronic Data Capture (REDCap) version 5.1.1, which is a secure, web-based application for building and managing online surveys and was designed to support data capture for research studies [23]. REDCap provides audit trails for tracking data manipulation and user activity, as well as automated export procedures for data downloads to common statistical analysis software programs [23]. All current first-, second-, third-, and fourth-year medical students in the University Track Medical Degree program at CWRU ( $n=$ 657 ) received the survey via email using REDCap. Medical students were given two weeks to complete and submit the survey online. No inclusion or exclusion criteria existed, except that participants were current medical students at CWRU. The study was deemed exempt by the CWRU Institutional Review Board under federal regulation 45 CFR $\$ 46.101(\mathrm{~b})$.

Respondents were asked to select their top three sources of nutrition information from a provided list (see Table 1). Government health agencies, peer-reviewed journals of nutrition and medicine, professional nutrition and health organizations, and RDs were considered "professional" resources. Consumer magazines and websites, phone apps, and television shows were considered "consumer" resources. Respondents had the option of selecting "other" and typing in a resource. In addition, they could select "I do not use nutrition resources." Respondents were determined to have chosen a majority of consumer resources if two or more selections were consumer. If they only selected two resources, one professional and one consumer, they were determined to have chosen a majority of consumer resources. If they selected "I do not use nutrition resources" but also selected one or more resources, they were determined to have chosen a majority of consumer resources if one or more of these 
TABLE 1: Nutrition resources included in the survey that respondents could select as being their top sources of nutrition information.

\begin{tabular}{ll}
\hline Professional resources & Consumer resources \\
\hline Government health agencies & Consumer magazines \\
$\begin{array}{l}\text { For example, http://usda.gov/, http://hhs.gov/, http://health.gov/, } \\
\text { http://www.choosemyplate.gov/ }\end{array}$ & $\begin{array}{l}\text { For example, Prevention, Men's/Women's Health, } \\
\text { Muscle Fitness, Self } \\
\text { Peer-reviewed journals of nutrition }\end{array}$ \\
$\begin{array}{l}\text { For example, American Journal of Clinical Nutrition, Journal of the Academy of } \\
\text { Nutrition and Dietetics, Nutrition Reviews }\end{array}$ & $\begin{array}{l}\text { For example, http://WebMD.com/, } \\
\text { http://MayoClinic.com/ }\end{array}$ \\
$\begin{array}{l}\text { Peer-reviewed journals of medicine } \\
\text { For example, Journal of the American Medical Association, New England Journal of } \\
\text { Medicine, American Journal of Preventative Medicine }\end{array}$ & Phone apps \\
$\begin{array}{l}\text { Professional nutrition organizations } \\
\text { For example, http://nutrition.org/, http://eatright.org/, http://nutritioncare.org/ } \\
\text { Professional health organizations }\end{array}$ & Television shows \\
$\begin{array}{l}\text { For example, http://diabetes.org/, http://cancer.org/, http://americanheart.org/, } \\
\text { http://ama-aasn.org }\end{array}$ & \\
Registered dietitians & \\
\hline
\end{tabular}

TABle 2: Nutrition topics (based on the DGAs) included in the survey for which respondents were asked to report feelings of competency.

(1) Preventing and/or reducing overweight and obesity through improved eating and physical activity behaviors

(2) Reducing sodium intake and recommendations for daily intake

(3) Replacing unhealthy fats with healthier fats

(4) Choosing whole over refined grains

(5) Limiting alcohol consumption

(6) Selecting healthier protein foods

(7) Increasing vegetable intake

(8) Increasing potassium intake

(9) Increasing dietary fiber intake

(10) Increasing calcium and vitamin D intake

resources were consumer. If their only selection was "I do not use nutrition resources," it could not be determined if they had chosen a majority of consumer resources. These respondents were placed into a separate category with others who responded the same. If respondents selected "other," they were required to provide further explanation; based on the information provided, it was determined whether this "other" resource was consumer or not (and these "other" resources are provided in the Results section).

Respondents were given a list of ten nutrition-related topics based on the DGAs (see Table 2). They were asked to respond "yes" to each topic if they felt competent to provide basic nutrition education about it to patients, "no" if they did not feel competent, and "unable to assess" if they felt unable to assess their competency level. Respondents were determined to feel competent to provide basic nutrition education according to the DGAs if they answered "yes" for at least seven of the ten topics.
The data collected in REDCap was exported to JMP Pro (Version 10.0.1, 2012, SAS Institute Inc., Cary, NC) for statistical analysis. Data was expressed as percentages of total responses. Binomial regression was performed to determine (1) if a majority of respondents chose consumer resources and (2) if a majority of respondents reported feelings of competency and (3) to evaluate differences in regard to gender and medical school year. A $P$ value of $<0.05$ was considered significant.

\section{Results}

The survey was distributed to all current first-, second-, third-, and fourth-year medical students in the University Track Medical Degree Program at CWRU $(n=657)$. Of the 657 medical students who received the survey, 308 fully completed it. Four completed it without specifying gender. These partially completed surveys were included in data analysis, giving a $47 \%$ response rate $(n=312)$.

Gender and medical school year distributions were fairly even. Fifty-two percent of respondents were female $(n=$ $161) ; 48 \%$ were male $(n=147)$. In comparison, the gender distribution of all medical school students at CWRU was $45 \%$ female and $55 \%$ male $(n=657)$. In addition, thirty percent of respondents were first-year medical students $(n=95), 24 \%$ were second-year medical students $(n=74), 21 \%$ were thirdyear medical students $(n=66)$, and $25 \%$ were fourth-year medical students $(n=77)$.

Respondents selected professional nutrition resources more often than they selected consumer nutrition resources. Of all the nutrition resource selections made, 371 were professional, and 296 were consumer. Figure 1 demonstrates the percentage of total respondents who reported using each of the nutrition resources listed in the survey. The most popular individual choice selected out of all of the resource options was consumer websites, followed by government health agencies. The third most popular individual choice was "I do not use nutrition resources." Thirty respondents 


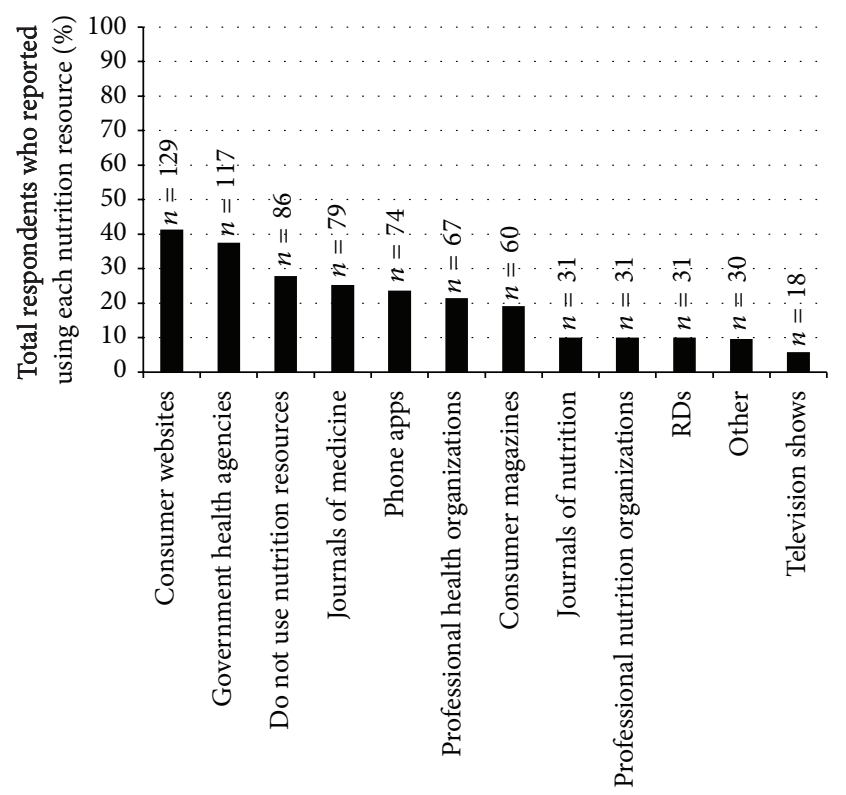

FIGURE 1: CWRU medical students' reported use of nutrition resources.

selected "other"; explanations provided included consumer books such as In Defense of Food, undergraduate classes, textbooks, friends, PCPs, the news, blogs, and websites including Wikipedia, UpToDate, and Reddit.

Selection of resources did not vary greatly between genders (data not shown), except for the following significant differences. Males were significantly more likely than females to use journals of medicine $(P=0.01)$ and nutrition $(P=0.02)$ and to select "other" $(P<0.05)$. Females were significantly more likely to use government health agencies $(P=0.04)$ and phone apps $(P=0.01)$.

No specific pattern existed for medical school year distribution and choice of nutrition resources (data not shown). First-year medical students were significantly less likely than fourth-year medical students to select journals of medicine $(P=0.01)$ and were significantly more likely to select phone apps $(P=0.02)$ and television shows $(P<0.01)$. Second-year medical students were significantly less likely than fourthyear medical students to select phone apps $(P=0.01)$ and significantly more likely to select "I do not use nutrition resources" $(P=0.02)$ and "other" $(P=0.02)$. Third-year medical students were significantly more likely than fourthyear medical students to select "other" $(P=0.05)$.

The data did not support the hypothesis that a majority of medical students would identify consumer over professional resources as their top sources of nutrition information. Fortytwo percent of respondents selected a majority of professional resources $(n=132), 38 \%$ selected a majority of consumer resources ( $n=119)$, and $20 \%$ selected "I do not use nutrition resources" and did not select any resources $(n=61)$.

Figure 2 illustrates medical students' reported feelings of competency in providing basic nutrition education to patients about nutrition guidelines (according to the DGAs). Over half of respondents reported feeling competent to

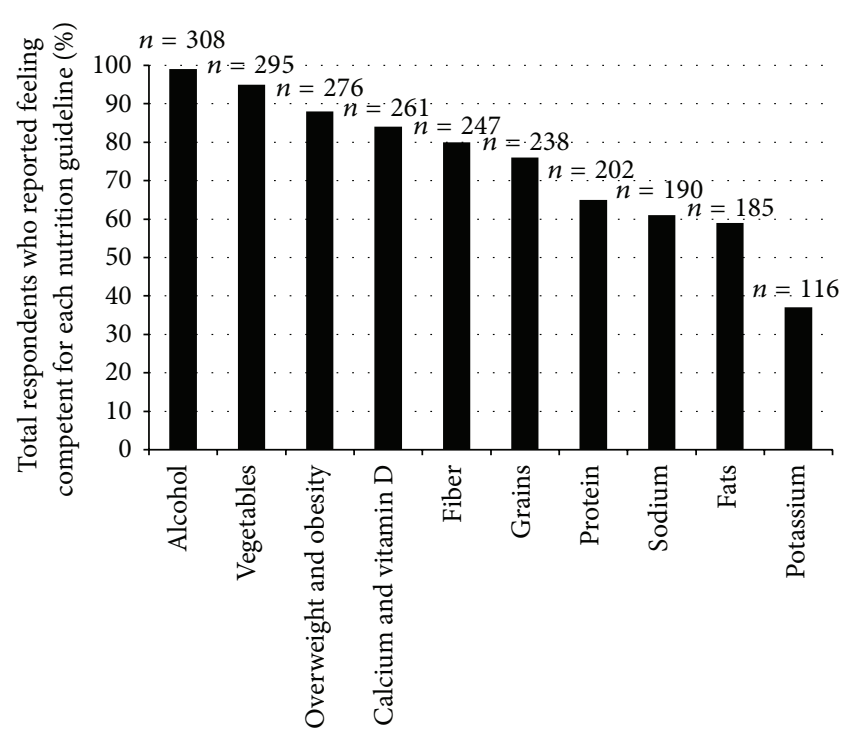

FIGURE 2: CWRU medical students' reported feelings of competency in providing basic education to patients about nutrition guidelines (according to the DGAs).

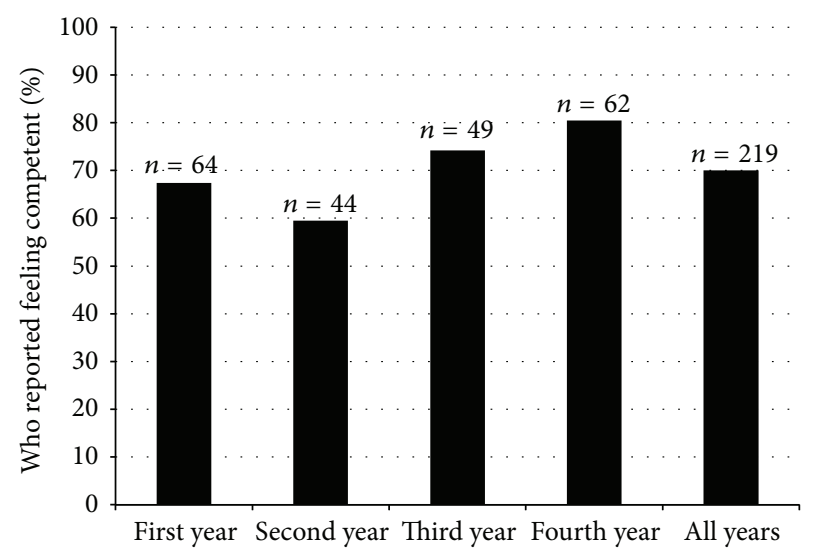

FIGURE 3: CWRU medical students' reported feelings of competency in providing basic nutrition education related to their year in medical school.

give education for 9 of the 10 nutrition guidelines. Almost every respondent reported feeling competent to give education about limiting alcohol intake, and 95\% reported feeling competent to provide education about increasing vegetable intake. The one guideline for which less than half of respondents reported feeling competent about was increasing potassium intake.

Only a few significant differences existed between genders and year in medical school (data not shown). Females were significantly more likely than males to feel competent to give education about grains $(P=0.04)$. Overall, fourth-year medical students felt the most competent to provide basic nutrition education (80.5\%), followed by third-year medical students $(74.2 \%)$, and then first-year medical students (67.4\%). Second-year medical students felt the least competent (59.5\%) (see Figure 3). First-year medical students were 


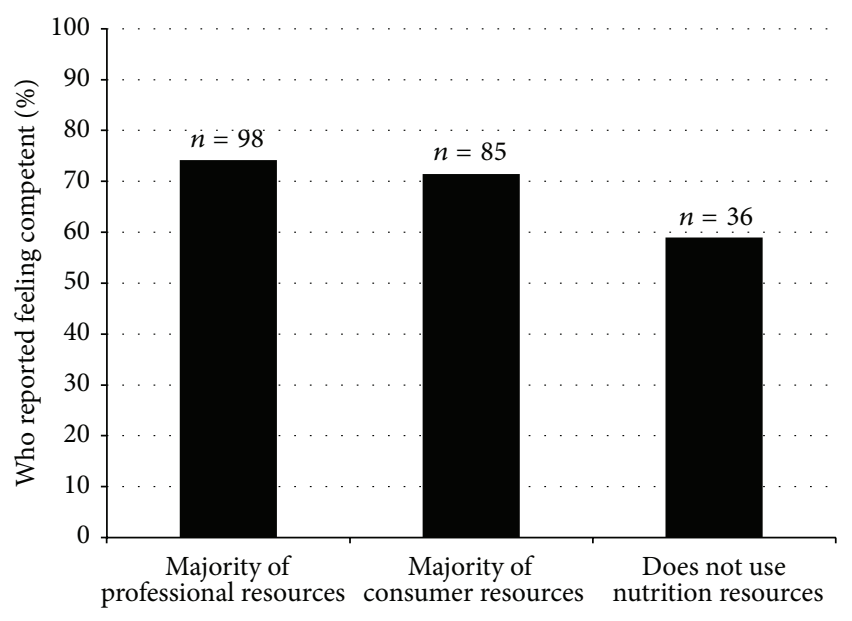

FIGURE 4: CWRU medical students' reported feelings of competency in providing basic nutrition education related to types of nutrition resources used.

significantly less likely than fourth-year medical students to feel competent to provide education about sodium $(P=$ 0.01). Second-year medical students were significantly less likely than fourth-year medical students to feel competent to provide education about overweight and obesity $(P=0.04)$, potassium $(P<0.01)$, and fiber $(P<0.01)$.

Data also contradicted the hypothesis that a majority of medical students would not feel competent to provide basic nutrition education according to the DGAs. Seventy percent reported feeling competent in their ability to provide nutrition education for at least seven of the ten dietary guidelines ( $n=219)$. However, the data supported the hypothesis that self-perceived level of competency increased with year in medical school, with the exception of secondyear medical students feeling less competent than first-year medical students.

The data indicated that reported feelings of competency in providing basic nutrition education were similar for respondents who reported using a majority of consumer resources and those who reported using a majority of professional resources (see Figure 4). Of respondents who chose a majority of professional resources, $74.2 \%(n=98)$ reported feeling competent; $71.4 \%(n=85)$ who chose a majority of consumer resources reported feeling competent. However, only $59 \%(n=36)$ of respondents who reported not using any nutrition resources also reported feeling competent, making these respondents significantly less likely to feel competent to provide basic nutrition education $(P=0.04)$ than other respondents.

\section{Discussion}

The survey had a fairly high response rate of $47 \%$. Medical students who chose not to respond to the survey may have had a lack of interest in nutrition or may have felt that nutrition is insignificant to their medical specialty of interest. As already discussed, physicians appear to recognize the importance of nutrition education in their practice. However, some medical students may not yet understand or value this relationship. Another potential deterrence could have been the time required to complete the survey, but it is unlikely that time was a major factor in participants' decision to respond because they were notified that the survey took less than two minutes to complete.

A slightly greater percentage of medical students chose a majority of professional nutrition resources over consumer resources, as their top sources of nutrition information, $42 \%$ versus $38 \%$, respectively. Overall, more individual selections of professional resources were made. However, the most commonly selected individual resource was consumer websites. Also, a large percentage of respondents (20\%) reported not using any nutrition resources. Therefore, many of the medical students who responded to the survey may be getting nutrition information from unreliable sources.

Results showed that first-year medical students were significantly less likely to use journals of nutrition and significantly more likely to use phone apps and television shows as nutrition resources than were fourth-year medical students. Perhaps as medical students progress through their medical education, they gain more knowledge about which nutrition resources are reliable and hence are better choices. However, results also indicated that first-year medical students were more likely to use journals of nutrition and professional nutrition organizations and less likely to use consumer magazines than fourth-year medical students, although these results were not significant. Therefore, it is difficult to conclude if medical students develop habits of choosing more reliable nutrition resources as they advance through medical school.

More than half of respondents reported feeling competent to provide basic nutrition education to patients about all of the nutrition-related topics (according to the DGAs), except the one regarding potassium. Interestingly, medical students' perceived level of competency in providing basic nutrition education appeared to increase as they advanced through medical school. The one exception to this pattern was that second-year medical students reported feeling less competent than first-year medical students. Perhaps students tend to enter medical school feeling as if they know more than they actually do. As they get further into their medical education, maybe they begin to realize the amount of information they have yet to learn. When they reach their third and fourth years, their level of competency likely increases as they gain more knowledge about nutrition-related topics, especially during their exposure to patients and RDs during clinical rotations. In addition, it is interesting to note that secondyear medical students were significantly more likely to select "I do not use nutrition resources" than fourth-year medical students. The data indicated that students who were not using nutrition resources were significantly less likely to feel competent to provide nutrition education. Perhaps part of the reason that second-year medical students felt the least competent was because they were significantly more likely not to use any nutrition resources.

Because many medical students are getting nutrition information from consumer resources or not using nutrition resources at all, it is possible that their nutrition information is unreliable. It is important to note that respondents who selected a majority of consumer resources were equally as 
likely to feel competent to provide basic nutrition education as those choosing a majority of professional resources. Thus, while medical students may feel competent to provide basic nutrition education, those using consumer resources could be passing along inaccurate information to patients.

A literature review showed that physicians are not frequently providing nutrition education to patients. Although this study did not assess actual competency, the data show that CWRU medical students appear to feel competent in their ability to give basic nutrition education. Therefore, lacking feelings of competency may not be the primary barrier hindering physicians from providing basic nutrition education to patients. Other barriers likely exist. Time is probably a key barrier in hindering physicians from speaking with patients about nutritional concerns. An average visit with a PCP is $10-20$ minutes $[15,24]$. The maximum amount of time that physicians usually spend on nutritional counseling is five minutes $[8,25]$. Even if physicians are willing to give nutrition education, time constraints could keep them from providing it.

Although physicians are an important source of nutrition information for patients, they may not be the best source unless they have also completed the education and training required of an RD. In a 2012 study surveying 500 general practitioners, family practitioners, and general internists in the USA, $41-48 \%$ of respondents reported that RDs were most qualified to be successful in helping obese patients [26]. Physicians likely have similar feelings about RDs being the most qualified in educating patients about other nutritionrelated topics. It is important that physicians refer patients to RDs who are considered the experts in the field of nutrition, especially when patients require beyond-basic nutrition education. It is also important that medical students learn about the role of RDs in interdisciplinary healthcare teams, so they have a general idea of what RDs do and when referrals are most appropriate.

The information gained from this study could be helpful in creating the best medical education for the 21st century. Perhaps curriculum should include teaching medical students about how to choose and locate reliable, professional nutrition resources to help increase the likelihood of basic education with more accurate nutrition information. The resources medical students use during their training will likely become the same resources used when they are practicing physicians. In addition, it would be extremely beneficial to ensure that medical students are taught about the value of referring patients to $\mathrm{RDs}$, who have much more education/training in nutrition and have more time available to spend educating patients about nutrition issues. It is certainly important that physicians are able to give accurate basic nutrition information to patients, but their decision to refer a patient to an $\mathrm{RD}$ could be the more valuable choice for many patients.

Limitations of this study include those that go along with using a survey. All responses were self-reported and were potentially inaccurate. The sample size was fairly small, only including 312 medical students. Also, results from this study at CWRU cannot be generalized to medical students at other universities, nor can they be translated into how these medical students will behave as practicing physicians. Only respondents' perceived level of competency in giving basic nutrition education to patients could be assessed, rather than their actual ability to give accurate nutrition education. Since perceived competency does not necessarily translate into actual ability, future research studies that explore the correlation between feelings of competency and actual competence would be enlightening. In addition, although the DGAs include many basic nutrition topics, medical students will likely have to educate patients about additional basic nutrition topics not included in the DGAs. Therefore, perceived competency in providing basic nutrition education may not be completely assessed using only the topics included in the survey. Last, respondents were asked to select their top three nutrition resources, but many selected only one or two, affecting data analysis. In addition, selection of "I do not use nutrition resources" and then selection of one or more resources also affected data analysis.

\section{Conclusions}

Many medical students at CWRU are getting nutrition information from consumer resources or not using nutrition resources at all. However, most of these medical students reported feeling competent to provide basic nutrition education to patients about a variety of topics. Because most medical students will become practicing physicians and will be responsible for providing sound nutrition education and guidance to patients, it is important that they learn how to differentiate between professional nutrition resources and unreliable, consumer-based resources. Referring patients to $\mathrm{RDs}$ is also a wise option to ensure that patients receive accurate nutrition education. Thus, medical school educators may benefit from expanding their nutrition curriculums to incorporate information about identifying reliable nutrition resources and the importance of referrals to RDs. The latter may help to promote the distribution of accurate nutrition information and increase the likelihood that patients receive evidence-based nutrition recommendations.

\section{Conflict of Interests}

The authors declare that there is no conflict of interests regarding the publication of this paper.

\section{References}

[1] National Center for Health Statistics, "Health, United States, 2012," Centers for Disease Control and Prevention, May 2013, http://www.cdc.gov/nchs/data/hus/hus12.pdf.

[2] American Academy of Family Physicians, Recommended Curriculum Guidelines for Family Medicine Residents: Nutrition, American Academy of Family Physicians, 2008, http://www.aafp.org/dam/AAFP/documents/medical_education_residency/program_directors/Reprint275_Nutrition.pdf.

[3] United States Department of Health and Human Services. Nutrition and weight status, http://healthypeople.gov/2020/ topicsobjectives2020/objectiveslist.aspx?topicId=29. 
[4] K. M. Adams, M. Kohlmeier, M. Powell, and S. H. Zeisel, "Invited Review: Nutrition in medicine: nutrition education for medical students and residents," Nutrition in Clinical Practice, vol. 25, no. 5, pp. 471-480, 2010.

[5] B. S. Levine, M. M. Wigren, D. S. Chapman, J. F. Kerner, R. L. Bergman, and R. S. Rivlin, "A national survey of attitudes and practices of primary-care physicians relating to nutrition: strategies for enhancing the use of clinical nutrition in medical practice," The American Journal of Clinical Nutrition, vol. 57, no. 2, pp. 115-119, 1993.

[6] K. S. Soltesz, J. H. Price, L. W. Johnson, and S. K. Tellijohann, "Family physicians' views of the preventive services task force recommendations regarding nutritional counseling." Archives of family medicine, vol. 4, no. 7, pp. 589-593, 1995.

[7] J. A. Cimino, "Why can't we educate doctors to practice preventive medicine?" Preventive Medicine, vol. 25, no. 1, pp. 6365, 1996.

[8] R. F. Kushner, "Barriers to providing nutrition counseling by physicians: a survey of primary care practitioners," Preventive Medicine, vol. 24, no. 6, pp. 546-552, 1995.

[9] M. L. Vetter, S. J. Herring, M. Sood, N. R. Shah, and A. L. Kalet, "What do resident physicians know about nutrition? An evaluation of attitudes, self-perceived proficiency and knowledge," Journal of the American College of Nutrition, vol. 27, no. 2, pp. 287-298, 2008.

[10] Association of American Medical Colleges, "2005 GQ All schools summary report [data set]," Obtained by special permission, September 2005.

[11] F. Torti, K. Adams, L. Edwards, K. Lindell, and S. Zeisel, "Survey of nutrition education in U.S. medical schools-an instructorbased analysis," Medical Education Online, vol. 6, p. 8, 2001, http://med-ed-online.net/index.php/meo/article/view/4526.

[12] K. M. Adams, K. C. Lindell, M. Kohlmeier, and S. H. Zeisel, "Status of nutrition education in medical schools" American Journal of Clinical Nutrition, vol. 83, no. 4, pp. 941S-944S, 2006.

[13] K. M. Adams, M. Kohlmeier, and S. H. Zeisel, "Nutrition education in U.S. medical schools: latest update of a national survey," Academic Medicine, vol. 85, no. 9, pp. 1537-1542, 2010.

[14] National Research Council (U.S.) and Committee on Nutrition in Medical Education, Nutrition Education in U.S. Medical Schools, National Academy Press, Washington, DC, USA, 1985.

[15] C. B. Eaton, M. A. Goodwin, and K. C. Stange, "Direct observation of nutrition counseling in community family practice," American Journal of Preventive Medicine, vol. 23, no. 3, pp. 174179, 2002.

[16] N. A. Anis, R. E. Lee, E. F. Ellerbeck, N. Nazir, K. A. Greiner, and J. S. Ahluwalia, "Direct observation of physician counseling on dietary habits and exercise: patient, physician, and office correlates," Preventive Medicine, vol. 38, no. 2, pp. 198-202, 2004.

[17] K. M. Kolasa and K. Rickett, "Barriers to providing nutrition counseling cited by physicians: a survey of primary care practitioners," Nutrition in Clinical Practice, vol. 25, no. 5, pp. 502-509, 2010.

[18] J. Tillotson, "Who's the average Joe eater to believe?" Nutrition Today, vol. 41, no. 3, pp. 112-114, 2006.

[19] K. M. Kolasa, “"Images” of nutrition in medical education and primary care," The American Journal of Clinical Nutrition, vol. 73, no. 6, pp. 1006-1009, 2001.

[20] S. M. E. van Dillen and G. J. Hiddink, "A comparison of Dutch family doctors' and patients' perspectives on nutrition communication," Family Practice, vol. 25, supplement 1, pp. i87i92, 2008.
[21] Case Western Reserve University School of Medicine, The Western Reserve 2 Curriculum: Reuniting Health and Medicine, Case Western Reserve University School of Medicine, 2013, http://casemed.case.edu/admissions/docs/Curriculum\%2011-12 .pdf.

[22] United States Department of Agriculture and United States Department of Health and Human Services, Dietary Guidelines for Americans, 2010 Executive Summary, United States Department of Agriculture Center for Nutrition Policy and Promotion Website, 2010, http://www.cnpp.usda.gov/sites/default/ files/dietary_guidelines_for_americans/ExecSumm.pdf.

[23] P. A. Harris, R. Taylor, R. Thielke, J. Payne, N. Gonzalez, and J. G. Conde, "Research electronic data capture (REDCap): a metadata-driven methodology and workflow process for providing translational research informatics support," Journal of Biomedical Informatics, vol. 42, no. 2, pp. 377-381, 2009.

[24] D. Mechanic, D. D. Mcalpine, and M. Rosenthal, "Are patients' office visits with physicians getting shorter?" The New England Journal of Medicine, vol. 344, no. 3, pp. 198-204, 2001.

[25] L. G. Nicholas, C. D. Pond, and D. C. K. Roberts, "Dietitiangeneral practitioner interface: a pilot study on what influences the provision of effective nutrition management," The American Journal of Clinical Nutrition, vol. 77, no. 4, pp. 1039S-1042S, 2003.

[26] S. N. Bleich, W. L. Bennett, K. A. Gudzune, and L. A. Cooper, "National survey of US primary care physicians' perspectives about causes of obesity and solutions to improve care," British Medical Journal, vol. 2, no. 6, Article ID e001871, 2012. 

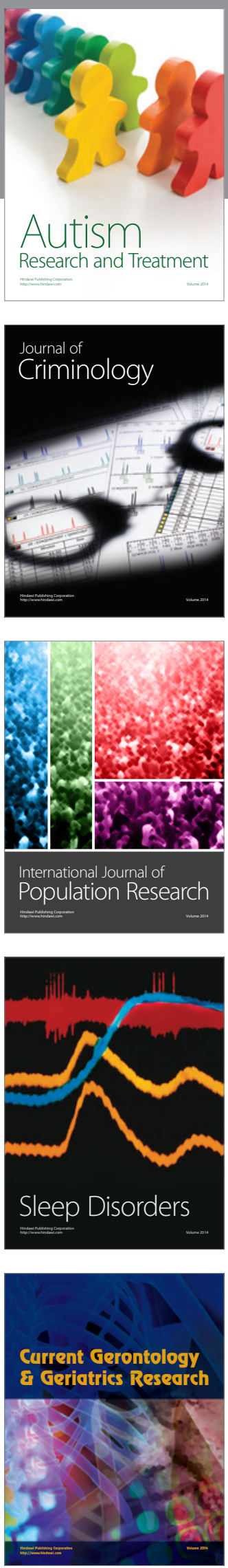
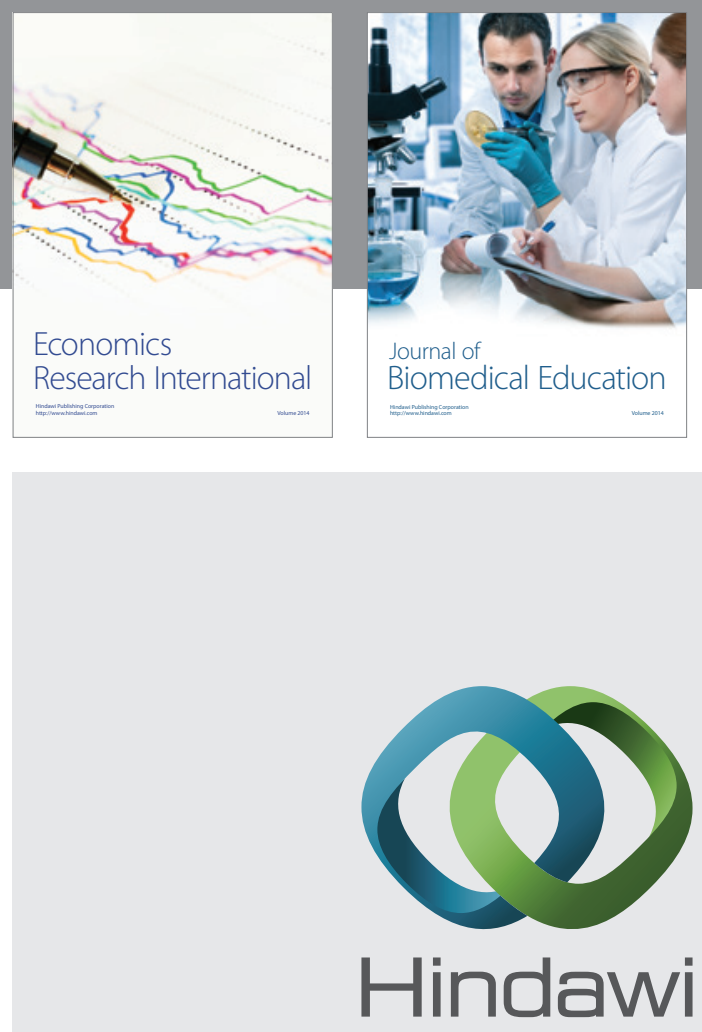

Submit your manuscripts at

http://www.hindawi.com
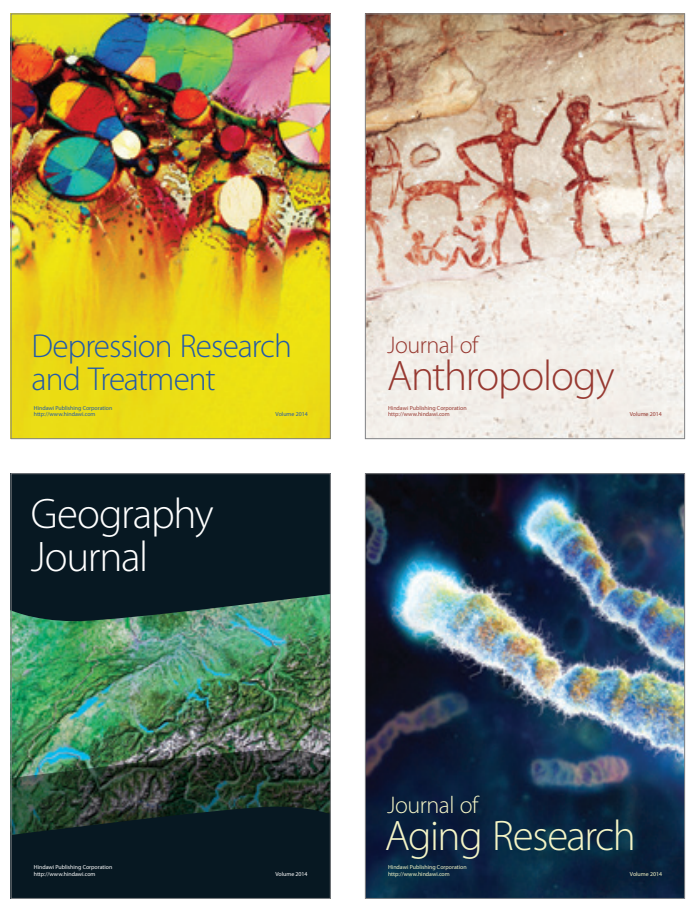
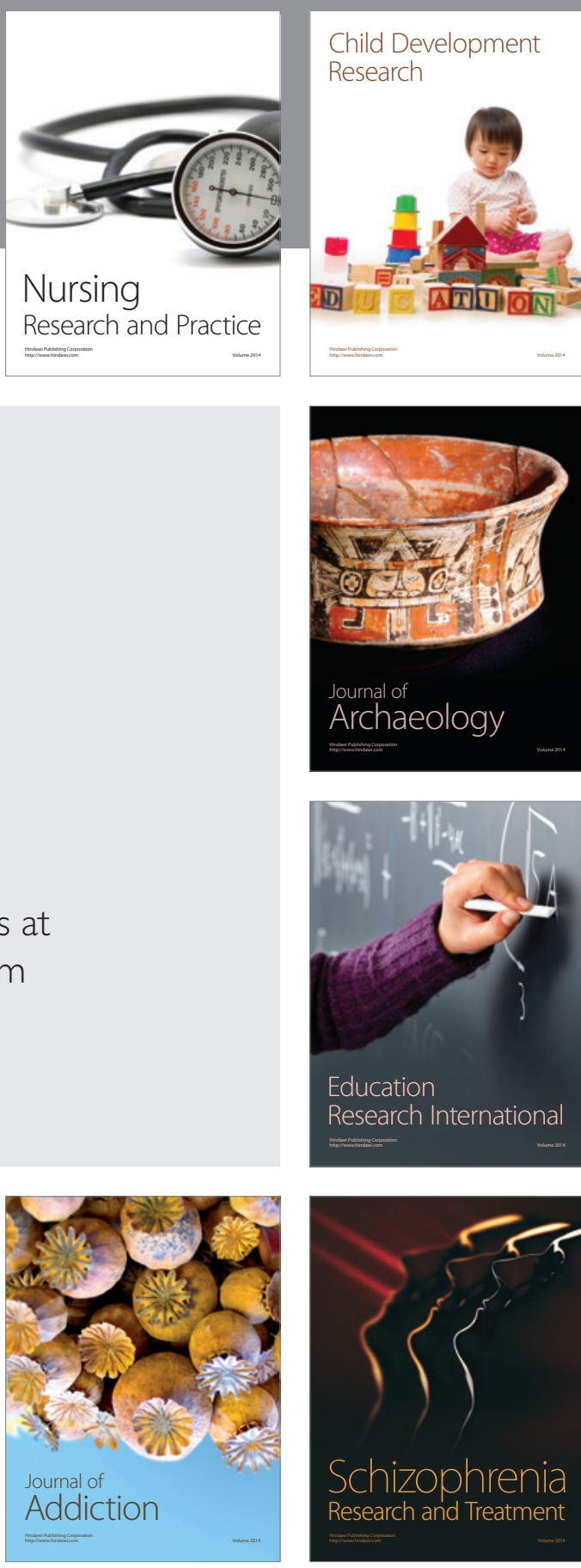

(D)
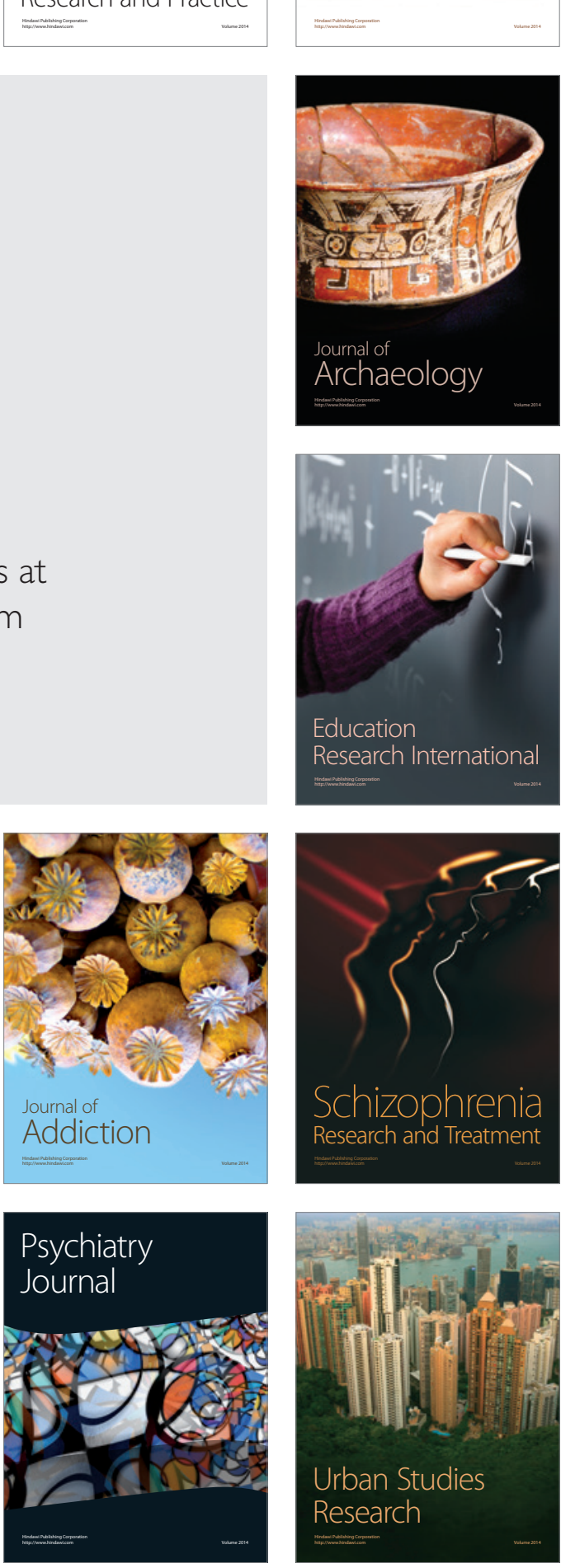